\title{
Productivity, Stability, Sustainability, Equitability and Autonomy as Properties for Agroecosystem Assessment
}

\author{
Gerald G. Marten \\ Environment and Policy Institute, East-West Center, \\ Honolulu, Hawaii 96848, USA
}

(Received 28 July 1987; accepted 10 August 1987)

\begin{abstract}
SUMMARY
The Southeast Asian Universities Agroecosystem network (SUAN) has used five system properties to assess agroecosystem performance: productivity, stability, sustainability, equitability and autonomy. Assessing these properties can be useful for agricultural research and development, but the assessment is complicated by several factors. First is the multidimensional character of these properties, due to (a) independent measures of agricultural production and (b) differences in the same property at different hierarchical levels of an agroecosystem. Secondly, there are significant limitations in generalizing agroecosystem assessment from one set of environmental and social conditions to another.

The SUAN network has examined trade-offs between these properties and implications of the trade-offs for agroecosystem design. Increases in productivity can be at the expense of other system properties, or they can be mutually reinforcing, depending on how the agroecosystem is organized.
\end{abstract}

\section{INTRODUCTION}

Agriculture is changing rapidly almost everywhere. Some of the changes are stimulated by government policies. Others appear to be spontaneous. What are the consequences of changes that are now in progress and changes that may take place in the future? This question has been a focus of research for scientists in SUAN-the Southeast Asian Universities Agroecosystem 291

Agricultural Systems 0308-521X/88/S03-50 (C) Elsevier 'Applied Science Publishers Ltd, England, 1988. Printed in Great Britain 
Network (Rambo \& Sajise 1985; Sajise \& Rambo, 1985; Soemarwoto \& Rambo, 1987; Rerkasem \& Rambo, 1988). Scientists in this network are charged with improving the agriculture in their regions by designing new cropping systems or fanning systems, selecting the most effective systems from an array of existing and potential alternatives, and anticipating problems that may arise as agriculture changes. To assist with these tasks, research in the SUAN network has assessed the performance of agricultural ecosystems (i.e. agroecosystems) in the context of how the agroecosystems are organized, how they function, and how the agroecosystems interact with the social systems of people who practice the agriculture (Rambo, 1982; Marten \& Saltman, 1986).

\section{SYSTEM PROPERTIES}

Agroecosystems are overwhelmingly complex. The numerous ecological processes that tie people, crops, weeds, animals, micro-organisms, soil, and water together into a functioning, on-going ecosystem are so intricate that they can never be fully described, nor can they be fully comprehended. Simplification is a practical necessity of analysis. Simplification is also essential for effectively communicating the results of analysis to agricultural practitioners. The dilemma is how to simplify without losing the essence of key relationships in the agroecosystem as a whole. One approach to simplification is system properties (also called agroecosystem properties in this essay), which combine large numbers of agroecosystem processes into single, highly-aggregated measures of performance that suggest how well an agroecosystem is meeting human objectives (Gypmantasiri et al, 1980; Conway, 1985; Rerkasem \& Rambo, 1988).

The SUAN network has focused on five system properties:

Productivity - the quantity of food, fuel or fiber that an agroecosystem produces for human use. Stability-consistency of production.

Sustainability — maintaining a specified level of production over the long term.

Equitability—sharing agricultural production fairly. Autonomy-agroecosystem self-sufficiency.

We refer to these properties as system properties (or 'emergent' properties) because they derive from the system as a whole rather than from any one of its parts. The productivity of a wet-rice agroecosystem is not determined simply by the yield potential of the particular rice variety that is employed. The yield that actually occurs depends upon the hydrological and 
nutritional environment the crop experiences at each successive stage of growth, which is, in part, a consequence of how farmers manage the crop. The rice productivity is therefore a consequence of the functioning of the total interactive agricultural-environmental-social system.

A major reason for evaluating properties such as those listed above is to compare the performance of alternative forms of agriculture (Conway, 1985; KEPAS, 1985). As a simple hypothetical example, imagine that a national irrigation system is to be extended to a previously rainfed area (Table 1).

With irrigation, productivity increases because yields per hectare are higher, because more crops can be grown each year, and possibly also because the improved water supply provides an opportunity to grow crops of higher value. If the irrigation system is reliable, stability also increases as farmers are liberated from the vagaries of rainfall. These gains are only sustainable, however, if the irrigated agriculture does not encounter serious problems such as salinization, a pest or disease that arrives on the scene and is prohibitively expensive to treat, or administrative problems in the irrigation system that cause its performance eventually to decline.

If fields near the main canal receive a better water supply than fields at the end of secondary canals, there may be considerable variation in production from one household to another. Equitability is less than it was without irrigation, when production was uniformly low. The automony of the farmers is reduced as they are compelled to deal with irrigation officials, as the farmers use exotic high-yielding varieties and associated technology (fertilizers, pesticides, etc.) to take advantage of the fact that water is no longer a limiting factor, and as they produce larger quantities of crops for a market economy.

It behooves anyone who is contemplating a new form of agricultural technology such as this irrigation system to consider all significant consequences, positive and negative. He can then decide whether it is really attractive on balance. Moreover, being alerted to the negative consequences, he can try to channel the changes to minimize the detrimental effects.

TABLE 1

Differences in the Agroecosystem Production Properties of Two Hypothetical Agricultural Technology Systems

\begin{tabular}{|c|c|c|}
\hline & Rainfed & Irrigated \\
\hline Productivity & Low & High \\
\hline Stability & Low & High \\
\hline Sustainability & High & Low \\
\hline Equitability & High & Low \\
\hline Autonomy & High & Low \\
\hline
\end{tabular}


While there are many good reasons to assess these agroecosystem properties, neither their measurement nor their interpretation is as simple or straightforward as we might like (Marten, 1986a; Marten \& Rambo, 1988). This essay discusses complications that the SUAN network has encountered while attempting to assess these system properties in a series of village case studies in Thailand, Indonesia, the Philippines and China (Rerkasem \& Rambo, 1988). There is no intention to suggest that the way these terms are used in this essay is their only proper use. Terms like productivity, stability, sustainability, equitability and autonomy can have numerous other legitimate meanings in various other contexts. The same applies to other terms such as agroecosystem, technology system, agroecosystem structure and agroecosystem function.

\section{IMPORTANT DEFINITIONS}

\section{Agroecosystems and agricultural technology systems}

It is necessary to start with some definitions, including the distinction between agroecosystems and agricultural technology systems (Fig. 1). An agroecosystem is a complex of air, water, soil, plants, animals, microorganisms, and everything else in a bounded area that people have modified for the purposes of agricultural production. An agroecosystem can be of any specified size. It can be a single field, it can be a household farm, or it can be the agricultural landscape of a village, region, or nation.

An agricultural technology system is the blueprint for an agroecosystem. It is a 'design', 'plan', or 'mental image' - the total package of technology which a farmer or community uses to mold a given area into an agroecosystem. An agricultural technology system specifies all the crops (and/or livestock) to be

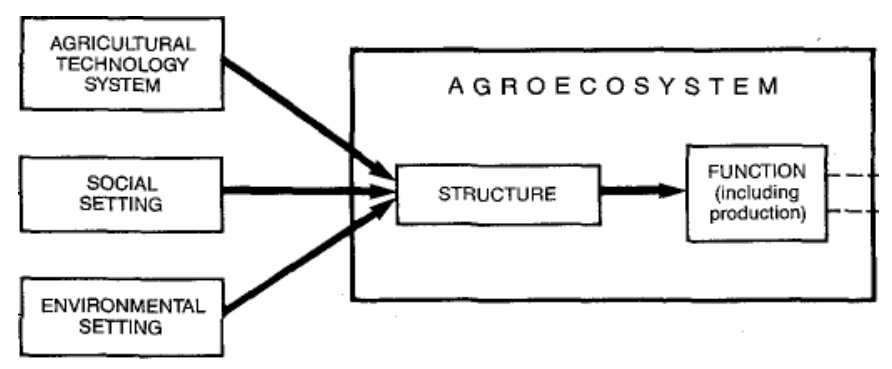

Fig. 1. Some basic definitions for agroecosystem assessment. 
employed, the spatial arrangement and temporal sequence of the crops, and all inputs to modify the environment so crops produce as they should. Agricultural technology systems embrace all that is customarily included in the concept of cropping systems, but agricultural technology systems are broader in the sense that they include everything that is done to shape an agroecosystem, including parts of the ecosystem that are not directly related to the crops.

Agricultural technology systems are important to farmers as their point of departure for molding the agroecosystems in which they work, but the technology systems are particularly important to agricultural scientists. When scientists try to improve agriculture, they are seeking better designs for technology systems, and it is through technology systems that scientists communicate the fruits of their efforts to farmers. (The 'technology' can be any form of agricultural knowledge, including traditional and informal knowledge as well as technology associated with modern science.)

Agricultural technology systems can be at any level of generality. For example, 'shifting cultivation' specifies a broad array of agricultural technologies, while the technology system for a mixture of maize and beans, explicitly designed for particular soil conditions at a particular location and season of the year, may be highly specific with regard to crop variety and cultivation practices. As a rule, a more general technology system applies to a broader geographic area, or a broader range of environmental and social conditions, while a specific technology system applies to a particular locality.

Agricultural technology systems are applied to specific pieces of landscape under specific environmental and social conditions to form realworld agroecosystems (Fig. 1). Just as the structure of a house is a consequence of not only an architect's blueprint, but also the particular site on which it is built, the specific materials available for construction, and the carpenter's skills and personal style with regard to details of construction, the same applies to agroecosystems. The structure of an agroecosystem is a consequence of not only its agricultural blueprint (i.e. the agricultural technology system) but also:

(1) its environmental setting (e.g. climate, soil, topography, various organisms in the area), which defines the material resources available for making an agroecosystem;

(2) the farmers and their social setting (e.g. human values, institutions and skills), which conditions how people interact with one another and the ecosystem in which they live, thereby determining how people actually apply their technology to mold the environment into an agroecosystem. 
The distinction between agricultural technology systems and agroecosystems is important because evaluations of agroecosystem performance may be directed toward one or the other. Sometimes we evaluate the system properties of specific, real-world agroecosystems, such as a specific field or village, but other times (as in Table 1) we evaluate the system properties of agricultural technology systems. Each agricultural technology system corresponds to an array of real or potential agroecosystems whose observed or inferred performance can be summarized in terms of system properties. As shall be seen below, evaluation of the system properties of agricultural technology systems is complicated by the fact that their performance is highly dependent on the environmental and social conditions in which they are applied.

\section{Agroecosystem structure and function}

Another distinction to keep in mind is that between agroecosystem structure and agroecosystem function (Fig. 1). Agroecosystem structure is how the agroecosystem is organized. It is a consequence of both an agricultural technology system and the environmental and social setting in which the technology is applied. Agroecosystem structure includes all elements of the ecosystem and how they are connected functionally to one another: i.e. all species of crops, livestock, weeds, pests, soil animals, and decomposer organisms - as well as all other plants, animals or micro-organisms that are present. It includes details of soil status and everything about inputs that shape the agroecosystem - the annual calendar of human activities in the fields, sources of labor (e.g. family labor or hired laborers), how much capital and energy (e.g. petroleum or beasts of burden) are employed, and where they come from (e.g. bank loans).

Agroecosystem function is a consequence of agroecosystem structure. Agroecosystem function consists of (a) movements of materials, energy and information from one part of the agroecosystem to another and (b) movements of materials, energy, and information in and out of the agroecosystem. Materials that leave the agroecosystem for human use are regarded as products. We refer to the quantity of these products as production, and system properties concerning production are the ones that customarily have received attention in SUAN research.

\section{EVALUATION OF SYSTEM PROPERTIES}

This section discusses some complications in assessing agroecosystem properties. It explains how each of the system properties for assessing production has a multiplicity of meanings. This is primarily because there are so many dimensions to production, but it is also because the properties 
can be very different at different levels of an agroecosystem hierarchy and under different environmental and social conditions.

\section{Multidimensional character of productivity}

We may wish for a property like productivity to be simple and unequivocal, but in fact it is highly multidimensional because agroecosystems have a variety of products for a variety of uses. Different measures- are more informative with regard to different functions of the products (Table 2):

— volume for building materials;

— biomass (i.e. weight) for plant residues or animal manure to be used as organic fertilizer;

— energy for wood or plant residues to be used as fuel;

- energy, vitamins, minerals, and amino acids for food;

- monetary value for exchange purposes.

Incidental outputs of agroecosystems, such as sediment in the water runoff from a field, can also be regarded as 'products', and each of these outputs has its own appropriate measure.

The significance of these different measures is that production of a single agroecosystem may be relatively high for one measure and relatively low for another. A clove plantation is high for monetary value, but low in biomass and food value. A taro field is relatively high in its production of some food values (e.g. energy), only moderate in other food values, and generally low in monetary value. Comparison of the production of different agroecosystems is therefore meaningful only when the unit of production is explicitly defined. Monetary value is the most universal measure of agroecosystem production, but no single measure - not even monetary value-is of universal significance.

An equally significant source of the multidimensional character of productivity is that productivity is only meaningful when expressed as production per unit of input (Table 2). Inputs take a variety of forms-land,

\section{TABLE 2}

Some Major Sources of Multidimensionality in Agroecosystem Productivity

Measures of production

Biomass

Food value

Energy

Monetary value

\section{Inputs}

Land area

Labor

Materials

Energy

Cash 
labor, energy, cash — and a single agroecosystem's productivity can be quite different with respect to each of the inputs. In general, productivity is high with respect to inputs that limit production and low with respect to inputs that are in excess. For example, where human population density is high, landholdings are small, and labor inputs are intensive (as in high-yielding wet rice cultivation), productivity per unit of land tends to be high but productivity per unit of labor is low. The opposite tends to be true for shifting cultivation in forests with a small human population.

The same is true when energy or cash inputs are intensified. In agriculture with heavy cash investments for modern inputs (e.g., fertilizers or pesticides), productivity per unit of land is high, but the net return on cash investments is low compared to traditional homegardens, for example, where cash inputs are much lower.

It may be desirable to express the efficiency of production with respect to very specific inputs. For example: production per unit of water input may be a primary concern in irrigation systems; production per unit of mineral nutrient input may be the major concern with regard to fertilizer costs or where soil nutrient depletion is a problem; production per unit of soil erosion may be the concern if loss of topsoil is imminent; petroleum energy inputs may be more important (particularly to a national government) than other energy inputs if petroleum is imported and therefore consumes precious foreign credits.

\section{Multidimensional character of stability and sustainability}

Stability concerns fluctuations in productivity that result from numerous fluctuations in an agroecosystem's physical and social environment: variations in rainfall, periodic pest attacks, price fluctuations, etc. Stability is assessed in terms of the fluctuation of production about a long-term average (Fig. 2) or the fluctuation of production about a long-term trend.

The stability concept can be described in abstract terms by considering movements of a small ball on the landscape, as in Fig. 3. The position of the ball on the landscape represents all the numerous aspects of agroecosystem organization and function, including production; point A represents the average condition of the agroecosystem (including its production). Stability concerns movement of the ball about point A under the impact of disturbances that are not large enough to knock the ball all the way out of the valley. Less movement (i.e. less fluctuation in production) represents greater stability.

Because stability derives from productivity, stability is multidimensional in exactly the same respects. A given agroecosystem can be relatively stable with regard to some measures of productivity and low with regard to others. 

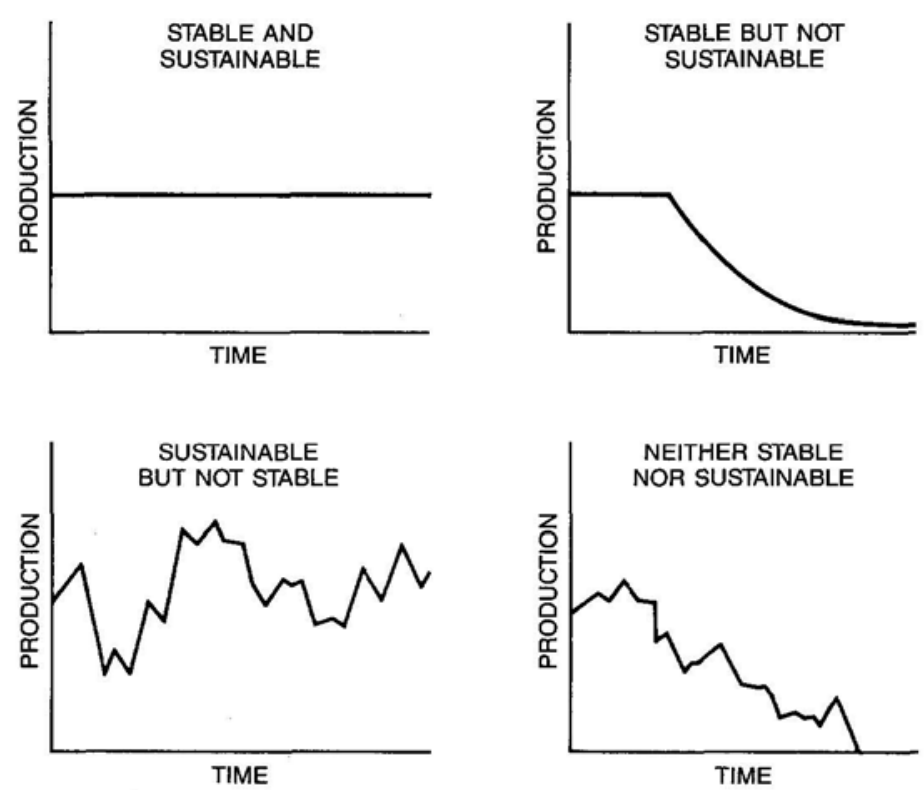

Fig. 2. The meaning of stability and sustainability in terms of the time course of production.

Maize production for subsistence can be considered stable as long as yields (and therefore food production) are consistent, but the same crop may be considered unstable if grown for a market economy with fluctuating prices.

Sustainability concerns whether a given level of productivity can be maintained over time (Fig. 2). In the abstract view of Fig. 3, sustainability involves the ability of farm management to maintain agroecosystem function (including production) at point $\mathrm{A}$, despite natural ecological processes that tend to change the agroecosystem toward point B. As with stability, sustainability has a variety of measures associated with various measures of productivity. Some measures of sustainability can be high while others are low for the same agroecosystem.

The multidimensionality of sustainability derives in large part from the fact that it may be necessary to increase certain inputs with successive crops to maintain yields at the same level. For example, if increasing fertilizer inputs are required to sustain production per hectare at a given level, the production per hectare may be sustainable even though production per unit

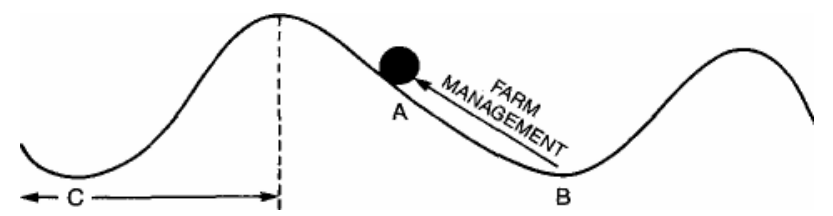

Fig. 3. A ball and landscape model for visualizing stability and sustainability concepts. The horizontal axis of the diagram represents different states of ecosystem structure and function. 


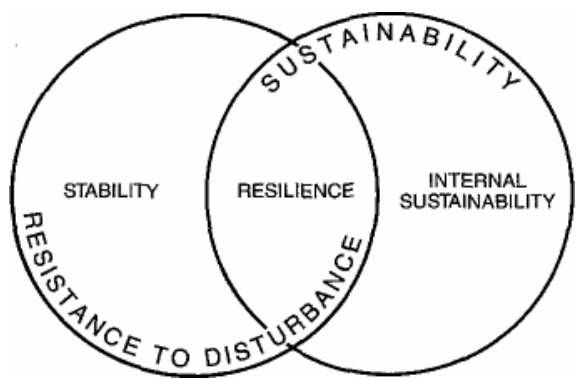

Fig. 4. Relationships of stability, resilience and sustainability.

cost is not. If weed problems require increasing labor inputs, production per hectare may be sustained while production per unit of labor is not.

There is another important sense in which sustainability is multidimensional. On the one hand, a lack of sustainability may be due to internal processes (ecological or social) that cumulatively undermine agroecosystem productivity - e.g. soil degradation, an increasing dependence on expensive pesticides as pests develop increasing resistance, stagnation of a bureaucracy or co-operative that provides essential inputs or marketing services. This is like movement of the ball from point A to point B in Fig. 3. On the other hand, an agroecosystem can lack sustainability because it fails to produce satisfactorily under the impact of traumatic external disturbances such as unusually severe drought, the appearance of a pesticide-resistant pest biotype, an increase in the cost of inputs (e.g. fertilizers), or collapse of an export market. This second sense of sustainability-which can be termed 'resilience' (Rolling, 1973)—concerns disturbances that threaten to knock the ball in Fig. 3 into a completely different valley (like the one designated byC).

Resilience is intermediate between stability and internal sustainability (Fig. 4). Like stability, resilience concerns the response of production to external disturbance; like sustainability, resilience concerns the maintenance of production. Stability concerns routine fluctuations in response to frequent and generally tolerable disturbances, while resilience deals with whether the agroecosystem can persist in the face of disturbances that are occasional but traumatic. The same agroecosystem can be quite strong with regard to internal sustainability but low in resilience, or visa versa, because these two kinds of sustainability involve different processes.

\section{Multidimensionality of equitability and autonomy}

Equitability is most commonly measured in terms of the evenness of distribution of agricultural products or income. A low coefficient of variation for the distribution among households indicates a high degree of 
equitability. Equitability may be assessed with respect to the distribution of agricultural products or with respect to access to inputs such as land, capital or technical information. Equitability of production and equitability in access to inputs are often closely linked, but not always. For example, fruit farmers may have equal landhqldings (i.e. high equitability for inputs) but very different incomes (i.e. low equitability for production), because some have contracts for high-paying urban markets while others must accept local market prices that are severely depressed during the harvest season.

Moreover, different measures of productivity can lead to different measures of equitability, in part because different kinds of agricultural products may be shared differently. For example, everyone in a community may have equal access to cropping fuelwood trees in ricefields, or the rats in ricefields (where people eat rats), but the rice production itself may be highly individualistic. In addition, access to inputs may be more equal with respect to some measures of production than it is for others. If all households have similar quantities of land, their opportunities for subsistence food production may be correspondingly similar, and equitability for food production is high. However, if they vary in their access to credit, technical information, or commercial markets, equitability for cash production may be low.

Autonomy is concerned with an agroecosystem's degree of integration, as reflected by: the movement of materials, energy, and information between its component parts; the movement of materials, energy, and information in and out of the agroecosystem; and control of those movements. Autonomy - which corresponds to less integration-is multidimensional because the magnitude of the flow of various materials, both within an agroecosystem and between the agroecosystem and the outside world, and the nature of the control of the flows, can be quite different for different materials in the same agroecosystem. The degree of autonomy with regard to inputs may be different from the autonomy in marketing agricultural products. The degree of local control over agroecosystem flows may be different from their magnitudes.

Different agricultural activities of the same household may vary radically in their autonomy. A household agroecosystem in Java may contain ricefields and commercial vegetable fields with a high level of purchased inputs and sales to an urban market, but the same household's homegarden may use few purchased inputs and produce primarily for home consumption. A farm household in Thailand may produce glutinous rice for home consumption but be tied to a market economy for other food items.

Even a single cropping system may be multidimensional with regard to autonomy. Control of irrigation water may be very much a community matter, but labor and cash inputs may be strictly up to the household. A 
cropping system may depend on outside sources for seeds or fertilizer but may use draught animals and household labor to be self-sufficient in energy and labor inputs.

\section{Hierarchical character of the system properties}

Agroecosystem properties are hierarchical because the agroecosystems themselves are hierarchical. Agroecosystems span a scale from single fields to the entire globe, and productivity, stability, etc., span the same scale. A single system property can be quite different at different levels of organization, and often there is a functional connection. The productivity of a shifting cultivation field may be high (per unit area of land) on the cultivated field itself, but the productivity may be low in terms of the total land area occupied by the entire shifting cultivation cycle (including forest fallow). High productivity at one scale (the cultivated field) may be a consequence of lower productivity on a larger spatial scale (i.e. the presence of fallows).

Variable production (i.e. low stability) of a particular cropping system can contribute to high household (or village) stability if the household (or village) uses year-to-year adjustments in the deployment of that cropping system to take up the slack for other cropping systems. For example, if a rice paddy is not able to secure sufficient water, a farmer may plant it to dryland field crops in mid-season. Production of rice and production of dryland crops each fluctuate from year to year, but total production (and total income) are buffered.

In a similar fashion the sustainability of a regional agroecosystem may be reinforced by relationships between component agroecosystems that tend to undermine the sustainability of some of those components. For example, erosion of upland ecosystems can provide silt that contributes to the sustainability of lowland agroecosystems. In some cases farmers may purposely encourage the erosion, or they may transport litter from forest ecosystems to use as mulch on their fields.

Equitability and autonomy can also be different at different scales. For example, communal agriculture may ensure equitability on a local scale but in some cases may lack individual incentives to stimulate higher levels of production that can be achieved under certain alternative forms of agricultural organization. The result may be a high level of equitability on a local scale but a low level of equitability on a regional scale because the equitable farmers have an average income less than other farmers. To take another example, irrigation may increase equitability among those who are fortunate enough to receive the irrigation (by providing them a uniformly abundant water supply), but disparities between farmers who do and do not have irrigation (where those without irrigation may become wage laborers 
for those who do) may decrease equitability on a larger scale. Turning to autonomy, agriculture in a tribal village may be highly integrated within the village but relatively isolated from other villages.

Agroecosystem properties are also hierarchical because of the hierarchical character of human objectives that provide the context for assessing the properties. For example, private individuals tend to be interested in net productivity per unit of labor, whereas governments (which may be concerned with extracting a surplus from a given land area) may be more interested in gross productivity per unit of land. An individual farmer may consider high-yield rice to be a low productivity crop, particularly if government price control limits the income from rice and costly inputs to achieve high yields cut even further into profits. On the other hand, if national self-sufficiency in rice production is a government priority, an agroecosystem that produces the highest tonnage of rice per hectare may be considered most productive from a national perspective.

\section{Situational character of the system properties}

It would be convenient if we could say that the system properties of a particular agricultural technology system are the same everywhere in a given region. In fact, they are sensitive to environmental factors such as slope, soil quality and water availability that can change over distances as small as a few hundred meters. They are also sensitive to social factors that can change from village to village or household to household.

Taking stability as an example, an agricultural technology system whose yields are sensitive to water supply may be stable under rainfed conditions in a low-lying, poorly-drained soil where soil moisture is always high, but unstable on a well-drained slope where soil moisture fluctuates with rainfall. Income stability may be low for a crop that is tied into the price fluctuations of a market economy but high for the same crop when tied to national price supports.

Stability is also situational because it can depend on the magnitude or duration of the disturbance that induces fluctuation in production. For example, a drought of several weeks may destroy an annual field crop but scarcely affect production from fruit trees, so the fruit trees appear to be more stable. However, if the drought is severe enough, the fruit trees may be killed, which could mean five years or more before new trees are back in production; a new field crop could be planted and back in production within a few months. While the fruit trees in this example are more stable than field crops in the face of mild disturbance, the field crops are more stable (i.e. return more quickly to normal production) when the disturbance is severe.

The extent to which an agroecosystem is stable in the face of a particular 
disturbance can depend in a variety of ways upon the time pattern of the disturbance (Marten, 1986a): whether the disturbance is frequent or only occasional (e.g. whether farmers expect it and are prepared for it); whether the disturbance is regular or irregular in its occurrence (i.e. whether it is periodic in a way that strikes up 'resonances' in an agroecosystem); whether the disturbance occurs suddenly or cumulatively; whether it lasts a short time or a long time.

In the case of field crops and fruit trees, the sensitivity of stability to the duration of the drought is a consequence of two general stability components that sometimes oppose one another (Marten, 19860): (a) the sensitivity of production to disturbance (where less sensitive is more stable) and (b) the speed of recovery from disturbance. (In fact, each of these two components has been regarded elsewhere in one context or another to be the fundamental definition of stability.) Because this essay regards stability for agroecosystem assessment to be simply the consistency of production that is a resultant of such component processes, the essay does not deal with the components themselves. However, attention to components of stability (e.g. sensitivity to disturbance or speed of recovery) is crucial when analyzing relationships between agroecosystem structure and agroecosystem function in order to design more stable agroecosystems.

Sustainability is also situational. The sustainability of a highly erosive crop depends on whether it is grown on a slope and how deep the soil is. The sustainability of a technology system that makes the soil progressively acidic can depend on whether the soil contains iron and aluminum oxides that fix phosphorus under acidic conditions, thus making the phosphorus unavailable to crops. The sustainability of a technology system that removes large quantities of mineral nutrients depends on natural nutrient inputs and the magnitude of nutrient storage in the soil. The same technology system that would deplete a poor soil in a few years could continue without ill effects on a high-organic-matter, volcanic ash soil for centuries. The sustainability of irrigated agriculture in the face of salinization depends on the amount of water available to flush the soil. A technology system with expensive inputs can collapse because of cumulative debt loads under one credit regime but be fully sustainable under another.

Equitability of production can depend on the equality of access to inputs for production. A particular agricultural technology system may have low equitability in situations where a critical resource is scarce and some people have better access. However, the equitability of the same technology system could be high if all critical resources are abundant, so everyone has all he needs, or if local social institutions enforce equal access to scarce resources or equal distribution of production despite uneven access. For example: land is communally owned in some places but not others; some villages may require wealthy landowners to provide food to the poor when times are 
difficult, while others may not. Because it may be the custom in some households for the family breadwinners to have priority for food, while in other households all family members have equal claim, the same agroecosystem could be low in equitability (with respect to age and sex) in one household but not another, depending on whether they are producing enough food for all.

The autonomy of an agricultural technology system can depend very much on the degree of physical isolation where it is applied. The same crops and cultivation practices can be for subsistence in a remote area but for urban markets where there are roads.

\section{Conclusions on evaluation of system properties}

Given the multiplicity of possible measures for agroecosystem performance, which should we actually use? Which are the true reflections of productivity, stability, sustainability, equitability, and autonomy? The answer of course is that no single measure is correct. More than one measure may be needed, and different measures are appropriate for different circumstances.

The measures to be chosen are strictly a matter of judgement-judgement that can vary from one situation to another. The importance that people attach to different measures of productivity usually depends upon which inputs are in short supply and their position in society. Where land is abundant, productivity per unit of land may be of little importance compared to productivity per unit of labor. Where cash inputs tax the resources of a farm household, productivity with regard to cash inputs may be paramount while inputs that are regarded as free, such as land or family labor, may be of lesser consequence.

For objective analysis, we should keep value judgements at a minimum by using objective criteria for selecting one measure instead of another, but we should also recognize that intrusion of value judgements into the selection process is unavoidable. More important than pure objectivity is 'transparency'-rendering the analysis open to full scrutiny by others. The key to transparency is to be explicit about the precise measure that was used, thereby reaching beyond the ambiguities of broad terms like 'productivity' and 'stability'. Transparency includes being explicit about measurement units and whether an assessment of stability, sustainability, equitability or autonomy refers to production or to inputs.

We must also recognize that the ultimate purpose of evaluating agroecosystem performance is to attain better agroecosystems, a process squarely in the domain of value judgements. Here our judgements should concern the extent to which agroecosystems are meeting human objectives and avoid the presumption that one value or another of a system property is inherently good. We tend to assume that higher productivity, stability and 
sustainability are better. That may generally be so, but not always. Many of us also consider greater equitability, autonomy and solidarity to be better. However, others of us may take the opposite view, according to our ideological disposition and whether we view uniformity of wealth, social control, self-sufficiency, or dependence to be beneficial or threatening in our particular circumstances.

A potential source of confusion in interpreting agroecosystem properties (as in Table 1) derives from the fact that evaluation may be (1) general, referring to an agricultural technology system as it occurs (or might be used) over a range of environmental and social conditions in a particular region or (2) specific, referring to a concrete agroecosystem at a particular location. General evaluations tend to be based on rapid assessments of an agricultural technology system at a sampling of locations in a region. Interviews and visual observations tend to predominate. Specific evaluations tend to be based on numerical measurements and records at a single location.

For clarity of analysis, presentation of results should be explicit whether the object of evaluation is an agricultural technology system or an agroecosystem, so limitations in the evaluations can be appreciated. A single value (e.g. low stability) is not appropriate for general evaluation of a technology system whose performance varies widely over a range of environmental and social conditions in the area. It may be necessary to indicate a range of values (e.g. low-medium stability) or specify the particular conditions to which the evaluation applies. A description of the environmental and social setting should also accompany specific evaluations of intensively studied agroecosystems, to avoid extrapolation to environmental and social conditions that are not comparable.

Perhaps our most significant conclusion is that the multidimensional character of agroecosystem properties is compounded by their sensitivity to local environmental and social conditions. An agricultural technology system is not simply stable or unstable; it may be stable with respect to one kind of disturbance such as drought but not with respect to other kinds of disturbance such as insect attacks or price fluctuations. Evaluating stability is not a matter of simply judging whether or not a technology system is stable. The most useful assessment may address the question, 'Under what environmental or social conditions is the stability of the agricultural technology system satisfactory (or unsatisfactory)?' The same kind of question can be asked of sustainability, equitability, and any of the other system properties, in order to:

(1) determine which kinds of agroecosystems are most appropriate for which social and environmental conditions; and

(2) identify points of vulnerability in an agricultural technology system to suggest how it should be strengthened. 


\section{RELATIONS BETWEEN AGROECOSYSTEM PROPERTIES}

Persons responsible for cropping systems design and other aspects of agricultural development may be particularly interested in the trade-offs between different agroecosystem properties. Improvements in one system property (e.g. productivity or stability) should not be at the expense of other properties - or at least the cost should not be too great.

It would be convenient to have some simple and general rules to serve as guidelines for how agroecosystems function in this regard, such as 'If productivity increases, sustainability declines', but it is not easy to discern a pattern. Some highly productive agricultural technology systems are quite stable while others are not, and some low-productivity agricultural technology systems are stable while others are not. For example, intensive high-yield rice production has reliable yields in some areas but is not reliable in other areas because of pests such as the brown planthopper. Consistent relationships between productivity and the other system properties are equally elusive, but exploring those relationships can nonetheless provide some insights into agroecosystem design.

\section{Productivity, stability and sustainability}

There are numerous ways that high levels of productivity can have a positive impact on stability and sustainability. For example, higher productivity may be attained by increasing the harvests in bad years (i.e. irrigation to reduce the impact of drought, or pesticides to reduce the impact of pest attacks), thereby making harvests more even from year to year, increasing stability. Higher productivity can be associated with higher sustainability when a more productive crop provides a more complete cover for soil protection and contributes more crop residues for the maintenance of soil organic matter. Higher productivity can also be associated with higher stability or sustainability if it leads to household savings that give a household the capacity to deal with periodic problems that threaten production. In general, any attributes that increase 'fallbacks' and other adaptive mechanisms in an agroecosystem can increase both its stability and/or sustainability (Jodha \& Mascarenhas, 1983).

There are also many ways that productivity can be negatively associated with stability or sustainability. For example, higher productivity can be associated with lower stability if the higher production is achieved by means of high-yielding varieties that are more vulnerable than local varieties to fluctuating environmental stresses such as droughts and pest attacks-or if high yields lead to a glut on the market that depresses prices. Higher productivity can be associated with lower sustainability if production is at 
the expense of soil resources (e.g. by generating erosion, reducing soil organic matter or exporting soil nutrients), if the production is due to heavy inputs leading to major alterations in the ecosystem that eventually undercut production (e.g. irrigation leading to salinization or pesticides leading to the loss of natural enemies and the emergence of secondary pests), or if higher production is a consequence of labor inputs that place a strain on social institutions underlying the organization of agricultural production.

Higher stability can reduce sustainability in the face of occasional, severe stresses (i.e. reduce resilience) if, under stable conditions, the agroecosystem (and its inhabitants) cease to exercise their abilities to deal with stress (because there is no need to do so) and consequently lose that ability, even though they may eventually need it. Farmers with a steady supply of irrigation water have more stable yields than rainfed agriculturalists because they are liberated from the negative effects that short periods without rainfall can have on rainfed agriculture. However, they may also lose the agricultural technology they once had for rainfed agriculture, simply because they no longer need it. Drought-resistant varieties may be discarded and cultivation practices to make the most of limited soil moisture supplies may be forgotten. As a consequence, they may not have the means to prevent crop failure if the irrigation system should fail.

There are numerous other examples of this conflict between stability and resilience. Chemical fertilizers help to buffer farmers from spatial variations in soil quality in their fields. Because large amounts of labor are required to collect and transport animal manure or green manure to maintain organic matter levels, the effort may not seem necessary as long as chemical fertilizers can compensate for diminishing organic matter. However, the impact of an increase in fertilizer prices that forces farmers to reduce fertilizer use can be particularly severe if they have not taken the effort to maintain the organic matter content of their soil. To cite another example, the construction of flood control dams allows farmers to cultivate fertile flood plains without worrying about flood damage, but the 'once in a hundred years' flood that overruns the dams can cause damage on a scale far greater than would occur if the farmers pursued their agriculture and constructed their villages in constant expectation of floods.

In pest control, the use of chemical pesticides can increase stability, providing an opportunity to eliminate even the smallest pest losses. Indigenous pest-resistant crop varieties may be discarded, and the pesticides may eradicate the pests' natural enemies along with the pests. If a pesticideresistant strain of the pest should suddenly appear, the damage may be more serious than it would have been without pesticides, because natural enemies are no longer present to keep the pest abundance within reasonable bounds. Even if the development of pesticide resistance is gradual, it eventually may 
be necessary to increase the frequency of pesticide application to a point where the crop must be discontinued due to excessive pesticide costs.

\section{Productivity, equitability and autonomy}

There are numerous ways that higher productivity can contribute to greater equitability. Returning to the example of irrigation, an improved water supply increases productivity because it increases yields or provides an opportunity to grow high-value crops. Along with the increase in productivity there is greater stability for everyone if the water is distributed according to needs, and greater stability can lead to greater equitability because crop losses often do not afflict farmers at random. Before, when the agriculture was rainfed, losses were more severe for farmers whose land was poor in moisture retention and therefore vulnerable to drought. With irrigation, their yields can be more equal.

However, greater productivity and stability can also lead to lower equitability. If the overall supply of water is not sufficient to provide reliable irrigation to all farmers in the area, only some of the farmers may receive irrigation service. This will increase overall productivity of the area but will also increase the spread of incomes. To take another example, higher income productivity from cash crops such as temperate vegetables can be associated with severe market fluctuations. Farmers who are lucky enough to harvest when prices are high can make a fortune, but others (who harvest when prices are low) may lose money. Finally, where equitability is based on communal ownership, if productivity is increased by introducing outside technologies or opening up to outside markets, communal land ownership may not be compatible with the new modes of production or marketing. Even outside influences not directly related to the technical side of the agriculture may induce social changes that lead to individual land ownership, which can lead eventually to unequal landholdings.

There are many ways that productivity can lead to greater household autonomy. If productivity is achieved through labor intensification, such as triple cropping that demands intensive work all year round, people do not have so much time for village social activities (e.g. religious festivals) that are mechanisms for village control over households. If productivity and stability are attained through diversified farming activities, advantages of synchronizing village agricultural activities can be correspondingly diminished. If productivity is increased by means of modern agricultural technology or integration with a market economy or national bureaucracy, for which traditional village leaders have no particular knowledge or influence, their authority is correspondingly diminished. If every household is able to meet its own needs on a reliable basis, it may feel no need for dependence on other 
households or village authority. The same applies to autonomy with respect to the outside world. A village with surplus production has the financial resources to take care of itself (e.g. development and maintenance of its irrigation system) without depending upon the government, middlemen or other outside sources of assistance.

There can also be negative associations between productivity and autonomy. Higher productivity may decrease autonomy if it frees people from an attitude of everyone for himself due to scarcity. Higher production may be at a cost of dependency on the outside world for inputs or markets. At the same time, higher production can generate a surplus to be used for the purchase of outside goods, sales of agricultural products to the outside, or extraction of some of the surplus by outsiders (e.g. by government taxation or unscrupulous business arrangements). Some of the surplus may be used by the local elite or by government to reduce autonomy even further by reinforcing existing authority.

\section{Conclusions regarding relationships between agroecosystem properties}

When we consider logical possibilities for the mechanisms that tie one system property to another, we are compelled to conclude that both positive and negative relationships are possible between each of them. As properties of agroecosystem function, the system properties are endpoints of complex ecosystem processes that can lead to both positive and negative relationships. Whether positive or negative predominates depends upon how the agroecosystem is organized and the circumstances under which it is functioning. A useful question to ask about trade-offs is 'Under what circumstances is the relationship positive, and under what circumstances is it negative?'

In theory this question could be answered by observing the patterns of productivity, sustainability and other production properties as they occur in various kinds of agroecosystems in various environmental and social settings. Unfortunately, the number of cases that would be necessary before reliable patterns could emerge exceeds what would be feasible in the foreseeable future. We cannot rely on case study observations directed only toward production properties to generate hypotheses concerning trade-offs between them. Attention will also have to be directed toward the mechanisms responsible for positive and negative associations between these properties, mechanisms that stem from relationships between agroecosystem structure and agroecosystem function.

\section{AGROECOSYSTEM STRUCTURAL PROPERTIES}

Agroecosystem structure is a consequence of the particular crops and other components (weeds, animal pests, soil animals, micro-organisms, etc.) in an 
agroecosystem, the way those components are structured by farm management practices, and the way those components are related functionally to one another. SUAN research has dealt with numerous aspects of ecosystem structure and their relationships to agroecosystem function (Table 3). However, the SUAN network has not dealt much with agroecosystem structure at the same organizational level as system properties for agroecosystem production. It could be useful for agroecosystem research to identify those structural system properties (at the agroecosystem level of organization) that in fact have strong relationships with the production properties. Such structural properties could prove useful as guidelines for agroecosystem design.

\section{TABLE 3}

Examples of Relationships Between Agroecosystem Structure and Agroecosystem Function that have been Studied in the SUAN Network

\begin{tabular}{ll}
\hline \multicolumn{1}{c}{ Agroecosystem structure } & \multicolumn{1}{c}{ Agroecosystem function } \\
\hline & \\
Intercropping & Human nutrition \\
Intercropping & Pest damage \\
Annual/perennial crop rotation & Mineral nutrient cycling \\
Perennial/annual strip cropping & Erosion, annual/perennial competition \\
$\quad$ on slopes & \\
Institutions in irrigation societies & Irrigation water supply Minor \\
Double and triple cropping & nutrient depletion of soil Soil \\
Integration of crops and livestock & fertility maintenance Diffusion of \\
Communications between innovative & new agricultural technology \\
$\quad$ farmers and others & \\
\hline
\end{tabular}

There are numerous structural properties that deserve to be considered. For example: cropping intensity (e.g. the number of crops per year); diversity of crop varieties; cropping sequences through time (including, for example, the extent to which sequences resemble those in natural ecological successions); interplanting patterns (within a field or over a landscape mosaic); vertical stratification of interplanted crops; the intensity, balance, and reliability of agricultural inputs; equity of access to inputs; selfsufficiency (or dependency) with regard to inputs or markets; the degree and nature of social control of agricultural activities; the nature and extent of channels for disseminating technical information; and the character of key non-crop organisms in the agroecosystem (e.g. mycorrhizae, nitrogen-fixing organisms, or natural enemies of significant pests). The following example of how structural properties can determine an agroecosystem's adaptability will illustrate the kind of interplay of structural properties that can tie them to the system properties of agroecosystem function. 


\section{Agroecosystem structure and adaptability}

One approach to delineating functional connections between system properties of agroecosystem structure and production is to address select properties of agroecosystem function (in addition to those concerning production). Adaptability (Rolling, 1978) is an example of a functional property that can help to bridge the gap between structure and production (Fig. 5). Adaptability can contribute to stability and resilience by enhancing an agroecosystem's capacity to respond to disturbances in a way that keeps the agroecosystem functioning within acceptable limits for production. The same applies to maintaining the distribution of production (i.e. equitability) within acceptable limits. With regard to internal sustainability, adaptability can provide the means for adjustments that halt the degradation of essential resources for production (e.g. soil or human institutions). Adaptability can contribute to productivity because an adaptable agroecosystem can respond to opportunities for improving production. The discussion that follows will give some examples of agroecosystem structural properties that can be most important to adaptability.

Adaptability derives from a number of properties of agroecosystem structure, the most central of which is the corrective feedback loop (Fig. 6), a mechanism by which agroecosystem function can be returned within satisfactory limits whenever it passes outside those limits. For example, if soil fertility starts to drop due to a decline in organic matter or erosion of the topsoil, a farmer can correct the situation with systematic applications of plant residues or animal manures that protect the soil surface from erosion while adding to its organic matter. Corrective feedback requires several structural elements (Fig. 6): (1) a point of reference with regard to the condition or functioning of an agroecosystem (e.g. an acceptable range of soil fertility or crop yields); (2) a measure of how the agroecosystem is functioning (e.g. assessment of soil fertility or yields); (3) a comparison of the assessment with the reference; (4) an array of measures for corrective action.

Because corrective feedback loops can be effective only if the response is appropriate to the correction that is required, and a great variety of corrections may be appropriate for different situations, diversity of possible responses is a key to adaptability. Plant residues can be applied to organicmatter-poor soils only if the larger agricultural system has cropping systems that provide a surplus of plant material. Animal manure can be applied only if there are animals to produce the manure. The animals may not be there if, for example, water buffalo have been replaced by motorized equipment. A diversity of crops and technology systems offers an array of fallbacks for adapting to numerous possible disturbances (Jodha \& Mascarenhas, 1983). Recourse to drought-resistant crops can be crucial to the success of upland 


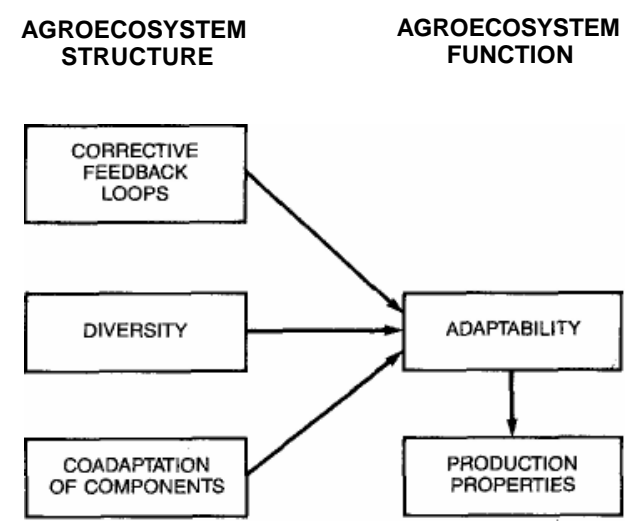

Fig. 5. An example of the causal connections between system properties of agroecosystem structure and system properties of agroecosystem production.

farmers during a dry year. Selecting different crops in response to market opportunities can contribute to financial stability.

However, having a wide array of cropping systems will not do much good if they are not jointly appropriate to needs that may arise. In other words, they must be able to function together. To be effective, agroecosystem diversity must be structured diversity, i.e. characterized by co-adaptation of agroecosystem components (Marten, 1984).

For example, a household can stabilize its overall rice production by planting a number of traditional rice varieties that are resistant to different pests and other environmental stresses, but only if the strengths and weaknesses of the varieties fit together into a coherent strategy (Rerkasem \& Rerkasem, 1984). A diversity of cropping systems can reinforce monetary

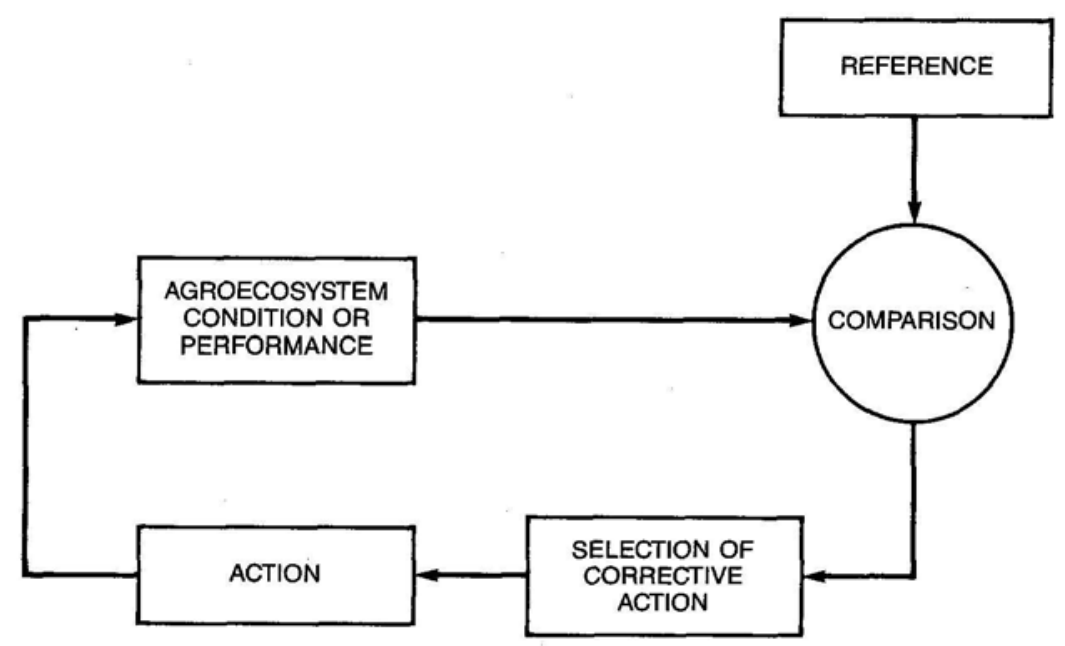

Fig. 6. Basic elements in a corrective feedback loop for adaptive agroecosystem design. 
productivity and stability by allowing farmers to adjust the areas they plant to different crops in response to market opportunities, but this works only if alternative crops are compatible with regard to soil conditions, seasonality, and other ecological features of the fields where they may be planted. Crop diversity can improve nutritional productivity only if there is a proper mix of crops (Abdoellah \& Marten, 1986): some that have high yields to produce large amounts of certain nutrients (e.g. calories and protein) that are needed in large quantities; and other crops that provide smaller quantities of a variety of nutrients for nutritional balance (e.g. vitamin A, vitamin C, riboflavin, calcium, and iron when rice is the staple food).

Interplanting a mixture of crops in the same field can provide a variety of feedback mechanisms to reduce pest damage, but only if it is the right mixture (Brown \& Marten, 1986). The wrong mixture can lead to more severe damage than in a monoculture. Crop diversity can contribute to ecological sustainability only if the different crops fill the various functions (e.g. nitrogen fixation, production of organic matter to maintain soil quality, and provision of ground cover to prevent erosion) necessary for maintaining a productive agroecosystem. Diversity can contribute to equitability if it provides everyone an opportunity.

It is worth looking to existing ecosystems for concrete examples of effective corrective feedback loops, diversity, co-adaptation and other structural system properties. Empirical research on the structure of natural ecosystems and existing agroecosystems-and the relation of agroecosystem structure to agroecosystem production - can draw upon the wisdom of centuries of biological and cultural evolution of ecosystem design (Marten, 19866).

\section{CONCLUSIONS}

Agroecosystem assessment will merit the attention of agricultural practitioners when it can relate the system properties of agroecosystem production to agroecosystem structure in simple and comprehensible terms. The foregoing discussion leads us to the encouraging conclusion that research on system properties of agroecosystem structure should be able to develop guidelines for agroecosystem design aimed at improving performance in a balanced fashion. To do this it will be necessary to identify agroecosystem-level structural properties that extend beyond the more elemental aspects of crops and management practices that customarily have formed the detailed basis for delineating agroecosystem structure. Prospects for success should be augmented considerably by attention to functional properties like adaptability that bridge the gap between structure and 
production. Relationships between the right system properties of agroecosystem structure and function should persist over a range of environmental and social conditions; i.e. they should be truly 'emergent'. This quality will increase their generality and their powers of extrapolation for suggesting the implications that broad features of agroecosystem design may have for agroecosystem performance.

\section{ACKNOWLEDGEMENTS}

The author wishes to thank A. Terry Rambo, Christopher Gibbs and the many scientists in the SUAN network for their numerous contributions to ideas presented in this essay.

\section{REFERENCES}

Abdoellah, O. S. \& Marten, G. G. (1986). The complementary roles of homegardens, upland fields, and rice fields for meeting nutritional needs in West Java. In: Traditional agriculture in Southeast Asia. (Marten, G. G. (Ed)), Westview Press, Boulder, Colorado, 293-315.

Brown, B. J. \& Marten, G. G. (1986). The ecology of traditional pest management in Southeast Asia. In: Traditional agriculture in Southeast Asia. (Marten, G. G. (Ed.)), Westview Press, Boulder, Colorado, 241-72.

Conway, G. (1985). Agroecosystem analysis. Agricultural Administration, 20, 31-55.

Gympmantasiri, P., Wiboonpongse, A., Rerkasem, B., Craig, I,, Rerkasem, K., Ganjanapan, L., Titayawan, M., Seetisarn, M., Thani, P., Rapeepan Jaisaard, Ongprasert, S., Radanachaless, T. and Conway, G. (1980). An interdisciplinary perspective of cropping systems in the Chiang Mai Valley: Key questions for research. Faculty of Agriculture, University of Chiang Mai, Chiangmai, Thailand.

Holling, C. S. (1973). Resilience and stability of ecological systems. Annual Review of Ecology and Systematics, 4, 1-24.

Holling, C. S. (1978). Adaptive environmental assessment and management, Wiley, New York.

Jodha, N. S. \& Mascarenhas, A. C. (1983). Adjustment to climatic variability in self provisioning societies. Some evidence from India and Tanzania. Patancheru, India: International Crops Research Institute for the Semi-Arid Tropics.

KEPAS (1985). The critical uplands of Eastern Java: An agroecosystem analysis. Indonesia: Kelompok Penelitian Agro-Ekosistem, Agency for Agricultural Research and Development.

Marten, G. G. (1984). The tropical rainforest as an ecosystem. In: An introduction to human ecology research on agricultural systems in Southeast Asia. (Rambo, A. T. \& Sajise, P. E. (Eds)), University of the Philippines, Los Banos, 61-74.

Marten, G. G. (1986a). Productivity, efficiency, stability, and sustainability as properties for agroecosystem assessment. Paper presented to the 'SUAN 
Workshop on Agroecosystem Analysis'. Khon Kaen, Thailand, January 6, 1986.

Marten, G. G. (1986b). Traditional agriculture and agricultural research in Southeast Asia. In: Traditional agriculture in Southeast Asia. (Marten, G. G. (Ed.)), Westview Press, Boulder, Colorado, 326-40.

Marten, G. G. \& Rambo, A. T. (1988). Guidelines for writing case studies of Southeast Asian rural ecosystems. In: Proc. Third SUAN/EAPI Research Symposium (Rerkasem, K. \& Rambo, A. T. (Eds)), Multiple Cropping Centre, Chiangmai University, Chiangmai, Thailand.

Marten, G. G. \& Saltman, D. M. (1986). The human ecology perspective. In: Traditional agriculture in Southeast Asia. (Marten, G. G. (Ed.)), Westview Press, Boulder, Colorado, 20-53.

Rambo, A. T. (1982). Human ecology research on tropical agroecosystems in Southeast Asia. Singapore J. Tropical Geography, 3, 86-99.

Rambo, A. T. \& Sajise, P. E. (1985). Developing a regional network for interdisciplinary research on rural ecology: The Southeast Asian Universities Agroecosystem Network (SUAN) experience. The Environmental Professional, 7, 289-98.

Rerkasem, B. \& Rerkasem, K. (1984). The agroecological niche and farmer selection of rice varieties in Chiang Mai Valley, Thailand. In: Introduction to human ecology research on agricultural systems in Southeast Asia. (Rambo, A. T. \& Sajise, P. E. (Eds)), University of the Philippines, Los Banos, 303-11.

Rerkasem, K. \& Rambo, A. T. (1988). Third SUAN/EAPI Regional Research Symposium. Multiple Cropping Centre, Chiangmai University, Chiangmai, Thailand.

Sajise, P. E. \& Rambo, A. T. (Eds) (1985). Agroecosystem Research in Rural Resource Management and Development. Proc. Second SUAN/EAPI Symposium on agroecosystem research. University of the Philippines, Los Banos, 183pp.

Soemarwoto, O. \& Rambo, A. T. (Eds) (1987). Impact of Development on Human Activity Systems in Southeast Asia. Proc. First SUAN/EAPI Regional Research Symposium. Institute of Ecology, Padjadjaran University, Bandung, Indonesia. 